\author{
Asian Economic and Financial Review \\ $\operatorname{ISSN}(e): \quad 2222-6737$ \\ $\operatorname{ISSN}(p): \quad 2305-2147$ \\ DOI: 10.18488/journal.aefr.2020.1010.1147.1168 \\ Vol. 10, No. 10, 1147-1168. \\ (C) 2020 AESS Publications. All Rights Reserved. \\ URL: wrwr.aessweb.com \\ check for
}

\title{
STRUCTURAL BREAKS, HYDROELECTRICITY AND ECONOMIC GROWTH: NEW FINDINGS FROM MALAYSIA
}

(iD) Farah Roslan ${ }^{1+}$
(iD) Esti Tri
Widyastuti $^{2}$

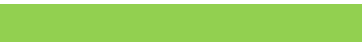

Article History

Received: 29 June 2020

Revised: 21 September 2020

Accepted: 6 October 2020

Published: 19 October 2020

\section{Keywords \\ ARDL \\ Hydroelectricity \\ Economic growth \\ Renewable energy \\ Structural breaks \\ Sustainable development \\ Malaysia.}

JEL Classification:

O1; Q2; Q3.

\author{
Centre for Fundamental Studies, Universiti Sultan Zainal Abidin, Kampus \\ Gong Badak, Terengganu, Malaysia. \\ Email:farahroslan@unisza.edu.my \\ ${ }^{2}$ Department of Economics, Business School, University of Aberdeen, United \\ Kingdom.
}

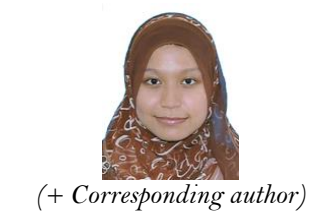

ABSTRACT

The aim of this study is to examine the relationship between hydroelectricity and real output in Malaysia by utilizing a neoclassical model from 1982 to 2015. Long-term behavior between hydroelectricity and real output was identified based on the result of the autoregressive distributed lag (ARDL) approach to cointegration. Meanwhile, the presence of causality between hydroelectricity and economic growth was established according to the results of the Granger causality via the vector error correction model (VECM). The results of the ARDL approach to cointegration indicate that a relationship exists between fossil fuels and hydroelectricity generation on economic growth. However, it is found that the hydroelectric sector has a higher impact on real output both in the short term and the long term. Next, the results of the Granger causality via VECM finds a negative unidirectional relationship from non-renewable to real output, implying that energy dependence on the conventional energy sector does not benefit the economic expansion of the country. Accordingly, it is important for policymakers to prioritize investments in alternative resources, especially in the hydroelectric sector, to ensure sustainable development in Malaysia. Likewise, ensuring availability of adequate labor is also essential for driving hydroelectric projects in the country.

Contribution/Originality: This study contributes to the existing literature on the linkages between renewable energy and economic growth by examining hydroelectricity and its association on real output in the time series analysis. This study is one of the few studies that accommodates the presence of structural breaks in the econometric approaches in the stationarity, cointegration and Granger causality.

\section{INTRODUCTION}

A viable and abundant amount of energy is crucial in the global community for ensuring the economic growth of a nation. Similar to other factors of production determinants, such physical labor, energy is viewed as an essential component in economic development (Azam, Khan, Bakhtyar, \& Emirullah, 2015). Chontanawat, Hunt, and Pierse (2008) suggest that energy occupies an important facet in boosting the economic mechanism, especially supply and demand. Regarding the supply facet, energy is a critical factor together with labor and capital, and it is viewed to exert a significant influence on the social and economic development of rural areas. On the demand aspect, energy acts a vital carrier to the purchaser, who decides to purchase the energy for their utility maximization. The literature also proposes that there should be a causal linkage between energy and output performance. Warr and 
Ayres (2010) and Stern (2011) add that growth in emerging economies is strengthened when there is an affordable, and better quality of energy input available. Thus, it is expected that energy is essential to well-being and prosperity across the globe. The influence of energy use on the output level has been extensively studied. Payne (2010) has documented a sizeable summary of this literature, comprising more than 100 empirical analyses between 1978 and 2008. Despite that, no consensus on the relationship between energy use and output level has been established. Currently, minimal studies have examined the potential of green energy sources and a country's economic development. Nevertheless, the availability of renewable energy depends on their level of development, availability and flexibility (Solarin \& Ozturk, 2015a). This is because each renewable resource has different features, and it would lead to wrong policy decisions if the assessments were only done based on overall renewable energy resources. For example, hydroelectricity provides a steadier electricity supply than wind energy due to wind power being subjected to supply disruption during cloudy days (Yah, Oumer, \& Idris, 2017). Besides the prominent role of hydroelectricity in the supply of energy, it has an advantage over other renewable energy sources in terms of irrigation, aquaculture and recreation (Kumar et al., 2011). Consequently, policy implications concluded from the causal connection between renewable energy and the level of output could be pertinent to certain energy sources and may not be applicable to all clean energy resources.

Following previous studies (e.g. (Apergis \& Payne, 2009; Ohler \& Fetters, 2014; Solarin \& Ozturk, 2015b)) the framework applied in this study is the sector-specific factors input, which is the first thorough procedure applied in the case of Malaysia, which includes hydroelectricity, non-renewables, labor and physical capital. This study focuses on Malaysia as a case study to explore the association between hydroelectricity and output performance for the subsequent justifications. First, Malaysia is the third biggest energy consumer in Southeast Asia; its energy requirement is three times the region's average (IEA, 2015). The economy is predicted to grow by $4 \%$ in the next 25 years (Ishak, 2014). This quick economic process has resulted in the country expanding its energy demand. Nevertheless, high dependence on fossil fuels has led to an energy supply security problem in the country. For instance, gas import has approximately doubled since 2008, including liquified natural gas (LNG) and pipeline imports from Indonesia since 2013 (IEA, 2015). This has led to Petroliam Nasional Berhad (PETRONAS) suffering substantial losses since it had to import LNG at higher market rates to meet local requirement. Therefore, to minimize geographic supply-demand imbalances within the country, diversification in the energy mix is critical to safeguard the sustainable growth of the country. Second, the country is currently working towards attaining a more balanced portfolio of electricity generation over the next few years by increasing its share in hydroelectric installation. Excluding China and India, Malaysia consistently ranked among the top 10 destinations with the world's largest new hydroelectric capacity installation during 2014 and 2015, leaving other countries in the region behind (see Table 1 and Table 2). The concern around energy security has contributed to the potential of the hydroelectric sector to offer alternative energy that is projected to have a significant influence in the electronic generation of a nation.

Table 1. Top 10 largest new hydroelectric capacity installation in 2015.

\begin{tabular}{c|c|c|c}
\hline Rank & Country & Capacity added (MW) & Generation (TWh) \\
\hline 1 & China & 19370 & 1126.40 \\
\hline 2 & Brazil & 2457 & 382.06 \\
\hline 3 & Turkey & 2225 & 66.90 \\
\hline 4 & India & 1909 & 124.65 \\
\hline 5 & Iran & 1040 & 13.79 \\
\hline 6 & Vietnam & 1030 & 62.63 \\
\hline 7 & Malaysia & 719 & 11.98 \\
\hline 8 & Canada & 708 & 375.53 \\
\hline 9 & Colombia & 599 & 49.00 \\
\hline 10 & Laos & 599 & 18.70 \\
\hline \multicolumn{2}{l}{ Source: IHA (2016). }
\end{tabular}


Alternative energy is a critical asset for many countries, yet Malaysia has not fully maximized hydroelectric resources. Although the share of hydroelectricity was approximately $11 \%$ in 2015, there has been a significant increase in the development of hydroelectric investment (IHA, 2016). In 2009, the government implemented the Sarawak Corridor of Renewable Energy (SCORE) plan that is designed to capitalize on the benefits of Sarawak state's vast natural capabilities by providing affordable electricity to its growing manufacturing base. The government has also identified 51 hydroelectric sites that could yield an approximate 20 giga-watts $(\mathrm{GW})$ of capacity through the SCORE program. Hence, the rationalization has established the usefulness of choosing Malaysia as a case study to assess the causal relationship between hydroelectricity and real output.

Table 2. Top 10 largest new hydroelectricity capacity installation in 2014

\begin{tabular}{c|c|c|c}
\hline Rank & Country & Capacity added (MW) & Generation (TWh) \\
\hline 1 & China & 21,250 & 1064.34 \\
\hline 2 & Brazil & 3312 & 392.58 \\
\hline 3 & Canada & 1995 & 375.11 \\
\hline 4 & Turkey & 1352 & 39.53 \\
\hline 5 & Russia & 1058 & 164 \\
\hline 6 & India & 1195 & 131 \\
\hline 7 & Colombia & 875 & 52 \\
\hline 8 & Malaysia & 836 & 10.14 \\
\hline 9 & Mexico & 760 & 31.53 \\
\hline 10 & Japan & 34 & 78.01 \\
\hline Source: IHA (2015). & & &
\end{tabular}

This investigation contributes to the current research in two ways. First, this research contributes to the literature that has examined the association between renewable energy and the level of output using a time series analysis to investigate hydroelectricity and its connection with real output. There has been limited research on the hydroelectricity-economic growth connection. Ohler and Fetters (2014) and Solarin and Ozturk (2015a) analyzed the importance of hydroelectricity for economic growth, and they focused on the effect of hydroelectricity on output level based on a panel dataset analysis. The benefit of a panel dataset estimation is that the technique is less vulnerable to the concerns linked with a short period of data, thus it provides more efficient estimates and better degrees of freedom. A time series estimation also has an advantage because it takes specific features of each country into account. This estimation captures greater knowledge, and a better strategy measure can be adopted for the specific country in the data set. In detail, this study conducts stationarity, cointegration and causality examinations within a production function framework set for the case on Malaysia.

Second, the existence of structural breaks in the cointegration, stationarity, and Granger causality approaches is also considered in this study. Much of the previous research between energy and output performance has either disregarded the existence of structural breaks in the variables in their evaluations or has only accommodated in either stationarity analysis or cointegration analysis. Similar research on hydroelectricity and economic growth has been examined by Solarin and Ozturk (2015b) in Latin American countries where the authors accommodated the existence of structural breaks in the variables in the stationarity and Johansen cointegration processes. Instead, this paper employs the autoregressive distributed lag (ARDL) bound test technique of cointegration to examine longterm behavior between electricity generation and output, which is superior in aiding short sampling and in the presence of structural breaks (Pesaran, Shin, \& Smith, 2001). The adoption of the ARDL bound test approach of cointegration for the long-term analysis is appropriate since the sample of the study comprises 33 observations. The Malaysian economy experienced the Asian financial crisis in 1997 and 1998; the ringgit was affected by other currencies in the Asian region and began to depreciate in July 1997 leading to a financial market collapse due to a series of asset bubbles. By 1999, the country showed signs of recovery and resumed GDP growth with its stock market, and currency depreciation significantly decreased (Ariff \& Abubakar, 1999). Ultimately, failure to 
accommodate the likelihood of structural breaks in the assessment procedure may lessen the strength in the null hypothesis rejection in the stationarity test, which leads to forecasting errors in the analysis (Perron, 1997).

The results of an ARDL cointegration with the existence of structural breaks validate the presence of longterm behavior between hydroelectricity and output growth, and this finding indicates that hydroelectricity is an input factor in addition to labor and capital. In addition, the results of the Granger causality from the vector error correction model (VECM) reveal a bidirectional relationship that exists between hydroelectricity and economic growth. Meanwhile, this study finds a negative unidirectional relationship from non-renewable to real output, implying that energy dependence on the conventional energy sector does not benefit the economic expansion for the country. Accordingly, policymakers need to prioritize investments in alternative resources, especially in the hydroelectric sector, to ensure consistent development in Malaysia. Likewise, ensuring adequate labor is also essential for steering hydroelectric projects in the country.

This study is divided into six sections. The first section is the introduction, section 2 provides a review of the literature, section 3 offers the methodology, which is followed by the empirical results in section 4 . Section 5 provides the discussion, and section 6 presents the closing statements and policy recommendations based on this study.

\section{LITERATURE REVIEW ON THE LINKAGES BETWEEN ENERGY AND OUTPUT PERFORMANCE ${ }^{1}$}

In the past, the associations between energy and economic expansion have been an intriguing subject in energy economics research and comprehensive works have been carried out to investigate the association between the two subjects. Early growth models, such as Solow (1956), assume that technological progress is exogenous and does not include natural resources in the improvement of technology. However, a small group of economists theorized that energy resources perform a central role in economic expansion besides being a central determinant of the industrial revolution, e.g. Apergis \& Payne, (2010). Other scholars, such as Hall, Tharakan, Hallock, Cleveland, and Jefferson (2003), proposed that productivity growth is due to the rise in energy use, or the technological progress in innovation that particularly leads to the increase in efficiency by permitting greater energy use. Accordingly, energy can be regarded as a possible foundation for an increase in output level, which has stimulated the interest of researchers in recognizing the disposition of the causality association between energy resources and output performance. Therefore, sound energy policies could be established once the causality direction between energy and output performance has been recognized.

The pragmatic analyses on the causal association between energy use and output level are combined into four verifiable premises; growth, conservation, neutrality and feedback (Sadorsky, 2010). For instance, the growth hypothesis suggests that electricity generation promotes output level, which indicates that electricity generation serves as an essential aspect in production. Therefore, any effort to restrict the activity of electricity generation may be detrimental to economic growth and any attempt to encourage electricity use will promote the level of output. The growth hypothesis postulated unidirectional causality from electricity generation to real output. Subsequently, the conservation hypothesis advocates that the economic development of a nation is less energy-dependent and that energy conservation policies are essential since they would not negatively influence economic development (Solarin \& Ozturk, 2015a). This premise is validated when unidirectional causality occurs from real output to electricity generation.

Third, the feedback premise suggests the electricity generation and output growth are interdependent. This hypothesis is accepted when bidirectional causality between electricity generation and level of output occurs. Last,

${ }^{1}$ The research on energy-economic growth has increased considerably. Payne (2010) provides a thorough revision in this subject. To keep it concise, this study scrutinises the bivariate and multivariate literature on renewable energy output using a production function approach in general. 
the neutrality premise suggests that electricity generation does not influence output performance and vice versa. This hypothesis is accepted when the causality between electricity generation and output growth does not exist. Therefore, any initiatives in the energy sector will not affect the real output and vice versa.

The reason why researchers have emphasized the linkages between natural resources and the level of output is the vision of sustainable growth. Many nations have decided to conserve energy and strengthen energy security along with reducing $\mathrm{CO}_{2}$ emissions, and this has amplified the attractiveness of research related to energy use and economic growth (Omri, Mabrouk, \& Sassi-Tmar, 2015). However, the escalation of sustainable development has encouraged more studies to examine the influence of renewable energy sources on output performance.

In line with the above-mentioned premises, this section focuses on assessing the empirical works on renewable energy and economic development. An early study that concentrated on multiple countries was conducted by Apergis and Payne (2010) who examined the connection between renewable electricity consumption and output for 20 OECD (Organization for Economic Co-operation and Development) members from 1985 to 2005 . The production function approach was employed by Apergis and Payne (2010) and the control variables of their study were labor and capital. The Pedroni cointegration (Pedroni, 2004) demonstrated long-term behavior between the renewables, output growth, and control variables. Additionally, the Granger causality test reported a feedback hypothesis between the consumption of renewable electricity and output in these nations. This result was substantiated by sequences of research by Apergis and Payne (2011a); Apergis and Payne (2011b); Apergis and Payne (2011c); Apergis and Payne (2011d) who investigated the causality association between electricity generated from clean energy and output in advanced and emerging countries. Empirical findings from many cases reported that panel cointegration demonstrated both long-term and short-term connections between the determinants. The series of studies validates the feedback hypothesis between clean energy electricity and output. However, the research only focused on the linearity effect between the variables without taking structural breaks into consideration. The multi-country studies were extended by Tugcu, Ozturk, and Aslan (2012) who examined which non-renewable or renewable energy was more significant for the level of output in G7 countries from 1980 to 2009. Besides the main variables, they included physical capital and labor as control variables and applied the ARDL cointegration technique and the Hatemi-J (2012) causality approach inside a Cobb-Douglas production model. Long-term behavior between the variables was demonstrated using the cointegration approach. In line with an analysis done by Apergis and Payne (2010); Apergis and Payne (2011a); Apergis and Payne (2011b); Apergis and Payne (2011c); Apergis and Payne (2011d), the evidence for a feedback hypothesis was supported.

In contrast, the neutrality hypothesis was supported by Ben Jebli and Ben Youssef (2015). A panel approach was utilized in their study to describe the causality link between fossil fuels and green energy consumption, trade openness, and real output. In a recent study of cross-country evidence, Al-Mulali, Fereidouni, and Lee (2014) explored the relationship between electricity usage from fossil fuels and the clean energy sector on output performance in 18 Latin American countries from 1980 to 2010. Their study employed a multivariate framework by integrating capital, labor, and trade openness as control variables. The result from the Pedroni (2000); Pedroni (2004) cointegration revealed long-term behavior between the variables. They also discovered feedback causality among energy sources and economic expansion. Nonetheless, it is recognized that renewable electricity is superior in boosting output development in the short term and long term compared with non-renewable electricity. In addition, the feedback hypothesis was also supported by Ohler and Fetters (2014) who investigated causality in the connection between economic growth and renewable electricity by energy origins, namely solar, geothermal, wind, hydroelectric and biomass of 20 OECD countries from 1990 to 2008. They contributed to the energy growth literature by scrutinizing electricity generation measured in MWh, and not electricity consumption, since electricity consumption refers to the energy supplied to end-user industries. 
One issue with multi-country studies, especially on the subject of energy growth, is that the findings obtained may suggest that all countries in the panel data estimation produce identical results Solarin and Ozturk (2015b). Therefore, the second part of the literature review concentrates on a single-country time series analysis.

Dogan (2015) employed the Cobb-Douglas framework and explored the links between electricity consumption from fossil fuels and alternative energy, and economic development in Turkey between 1990 and 2012. Other than the ARDL and Johansen cointegration methods, Gregory and Hansen (1996) cointegration was also used to identify any structural break among the variables. The result from ARDL, Johansen and Gregory-Hansen indicates that long-term behavior exists between non-renewable and renewable energy and economic growth. The outcome from the VECM Granger causality established the growth hypothesis between renewable electricity and output performance and the feedback hypothesis between non-renewable electricity and output performance. The growth hypothesis was supported for the case of Latin American countries by Solarin and Ozturk (2015a) who explored the causal linkages between hydroelectricity consumption and real output in seven Latin American economies from 1970 to 2012. The neoclassical model was employed by featuring labor force and capital as control variables. The Johansen cointegration with a structural break (Johansen \& Mosconi, 2000) revealed that all variables were cointegrated in the long term. The incorporation of the existence of a structural break into the VECM model and the outcome from the VECM Granger causality depicted a two-way long-term causality between hydroelectricity and output in Argentina and Venezuela. They also identified a long-term unidirectional causality running from hydroelectric source to output performance in Peru, Colombia, and Ecuador.

Existing literature on energy growth studies has endeavored to explore long-term and causality relationships between green energy and economic expansion by using energy in aggregate. However, there is limited research available identifying the association between energy and output by sources, and there are minimal studies that have contemplated the relationship between hydroelectricity and output level. Therefore, country-specific analysis is of interest to scholars and policymakers as it will enable them to obtain more consistent and accurate results from policies for energy diversification in order to attain sustainable growth. In addition, it is also noted that most of the econometric analyses on energy and economic growth, especially renewable energies, have failed to detect the occurrence of structural breaks in the series of data. Because countries are more likely to experience an unexpected structural shift in macroeconomic variables and in the energy market, the application of econometric techniques without accommodating any fluctuations in the series may cause forecasting errors in the estimation of the results.

As such, recognition of the connection between economic growth and hydroelectricity source is necessary for developing countries, especially in Malaysia. The main reason for this is the recent supply security problem, whereby there has been a reduction in domestic LNG production and a significant increase in demand for coal, which is imported from Indonesia (IEA, 2015). On the other hand, the proportion of hydroelectric sources shows an upward trend year on year. Consequently, hydroelectricity is expected to provide promising alternative energy for energy diversification after conventional energy sources. Answering this question is crucial for the establishment of a sound energy strategy in Malaysia to improve energy security in the country. Hence, a review of the literature has developed the research objective, which aims to examine the causal relationships between hydroelectricity and real output. Compared to previous research, this study employs the sector-specific production function that is the first inclusive technique applied in the case of Malaysia, which comprises labor and capital as control variables. In the existing literature there is limited research that accommodates the influence of specific energy sources on the level of output, which allows this study to scrutinize the causality impacts between hydroelectricity and output performance in the country. 


\section{METHODOLOGY}

\subsection{Model and Data}

This study examines if the causal linkages between hydroelectricity and income are consistent with existing energy growth literature, e.g. Apergis \& Payne, 2009; Sadorsky, 2009a, 2009b, by including hydroelectricity as an individual input together with non-renewable energy, labor and capital. Analyzing the relationship between hydroelectricity and non-renewables helps this study to distinguish which types of energy have a higher impact on output level in Malaysia. The following factors of production framework at year $t$ is specified as follows:

$$
Y_{\mathrm{t}}=f\left(H_{\mathrm{t}}, N R E_{\mathrm{t}}, L_{\mathrm{t}}, K_{\mathrm{t}}\right)
$$

In equation $1, Y$ is real GDP per capita; $H$ is hydroelectricity generation per capita; $N R E$ is non-renewable energy per capita, which comprises oil, natural gas and coal generation; $L$ is labor force; and $K$ is gross fixed capital formation (GFCF). The data for the real GDP is in billions of constant U.S. dollars (2000 prices) and were retrieved from the World Bank database, while data on hydroelectricity were retrieved from the Department of Statistics Malaysia and defined in kilowatt-hours $(\mathrm{kWh})$. Next, data on the labor force were measured in millions of workers and were retrieved from the Department of Statistics Malaysia. Last, since data and information on fixed capital stock are difficult to measure accurately, it is possible to acquire a relatively reliable measure of the stock of fixed capital. Thus, gross fixed capital formation (GFCF) is applied as an alternative measure for the growth of the capital stock. Essentially, the perpetual inventory method infers that the difference in variance of capital is roughly related to the variation in investment, assuming that the rate of depreciation is constant. ${ }^{2}$ Data on GFCF in billions of constant U.S. dollar (2000 prices) were retrieved from the Department of Statistics Malaysia. The per capita variable for each year is obtained by dividing each variable by the population figure for a particular year. This study applies yearly time-series information of Malaysia from 1982 to 2015 based on the data available for the country. Each series was converted to natural logarithms before the empirical investigation to remove any concern around distributional characteristics of the dataset (Mahalik, Babu, Loganathan, \& Shahbaz, 2017). Using natural logarithms, the linearized production function model at year $t$ is now detailed as:

$$
L Y_{\mathrm{t}}=\alpha_{0}+\alpha_{1} L H_{\mathrm{t}}+\alpha_{2} L N R E_{\mathrm{t}}+\alpha_{\mathrm{a}} L L_{\mathrm{t}}+\alpha_{4} L K_{\mathrm{t}}+\mu_{\mathrm{t}}
$$

In equation $2, L Y$ refers to the natural logarithm of real GDP per capita; $L H$ refers to the natural logarithm of hydroelectricity generation per capita; $L N R E$ refers to the natural logarithm of non-renewable energy generation per capita; $L L$ refers to labor force per capita; $L K$ refers to the natural logarithm of GFCF per capita; and $\mu$ refers to the residual term.

The summary of the descriptive statistics before and after the logarithm transformation is illustrated in Table 3 and Table 4. Table 4 shows the result from the Jarque-Bera test, which indicates that the chi-square value is less than 5.99 significance level, indicating that skewness and kurtosis match a normal distribution. Next, as presented in Table 5 , the high association between predictor variables may indicate a multicollinearity problem. As such, the presence of multicollinearity between the independent variables may contribute to non-significant parameter estimates and higher standard errors, which leads to questions over the precision of the coefficient estimates. A variance inflation factor (VIF) test was employed in this study to test for multicollinearity to eradicate any doubt on

${ }^{2}$ See Soytas and Sari (2006). 
multicollinearity. As demonstrated in Table 5, there is no proof to declare the existence of multicollinearity since the VIF for hydroelectricity and non-renewables generation, economic growth, capital and labor are less than 5.

\subsection{Unit Root Tests}

It is necessary to perform a stationarity test on the variables to examine if the series contains unit root (Lean \& Smyth, 2010). This is because when there is non-stationarity in the time series, it will create a false regression when the variables are found to have a unit root (Granger \& Newbold, 1974). Furthermore, the stationarity test was employed to establish that no data is integrated of order two, e.g. I(2) process. This is due to the ARDL regression by Pesaran et al. (2001) only being plausible when the stationarity of the series is an $\mathrm{I}(0)$, I(1) or mixed $\mathrm{I}(0)$ and $\mathrm{I}(1)$ process.

Table 3. Descriptive statistics before logarithm transformation.

\begin{tabular}{c|c|c|c|c|c}
\hline $\begin{array}{c}\text { Descriptive } \\
\text { Statistics }\end{array}$ & $\begin{array}{c}\boldsymbol{Y} \text { (Per Capita in } \\
\text { Constant USD } \\
(\mathbf{2 0 0 0} \text { Prices) }\end{array}$ & $\begin{array}{c}\boldsymbol{H} \text { (Per } \\
\text { Capita in } \\
\mathbf{k W h}\end{array}$ & $\begin{array}{c}\boldsymbol{N R E}(\text { Per } \\
\text { Capita in } \\
\mathbf{k W h})\end{array}$ & $\begin{array}{c}\boldsymbol{K} \text { (Per Capita In } \\
\text { Constant USD } \\
(\mathbf{2 0 0 0} \text { Prices)) }\end{array}$ & $\begin{array}{c}\boldsymbol{L}(\text { Per } \\
\text { Capita) }\end{array}$ \\
\hline Mean & 6453.422 & 261227.2 & 2685699 & 1685.686 & 0.403 \\
\hline Std. Deviation & 2150.236 & 67626.75 & 1236819 & 602.257 & 0.024 \\
\hline Max & 10509.21 & 465548.5 & 4642914 & 2799.851 & 0.471 \\
\hline Min & 3565.744 & 182165.5 & 1106090 & 671.569 & 0.373 \\
\hline Kurtosis & 1.828 & 5.167 & 1.676 & 2.157 & 4.266 \\
\hline Skewness & 0.169 & 1.567 & 0.187 & 0.666 & 1.373 \\
\hline Jarque-Bera & 2.403 & 19.954 & 2.602 & 3.386 & 13.998 \\
\hline
\end{tabular}

Four different unit root tests were conducted to assess the integrational qualities of the variables, explicitly, ADF (Dickey \& Fuller, 1979), PP (Phillips \& Perron, 1988), KPSS (Kwiatkowski, Phillips, Schmidt, \& Shin, 1992), and ZA (Zivot \& Andrews, 1992) on income, hydroelectricity generation, labor and capital. Nonetheless, the ADF, PP, and KPSS stationarity tests do not provide any intelligence about the existence of unknown structural breaks in the time series, declining the stationarity properties and causing minimal explanatory power (Mahalik et al., 2017). In order to address this limitation, the ZA stationarity approach was adopted to evaluate the probability of the existence of structural breaks in income, capital, labor, and hydroelectricity generation. The ZA unit root tests are rooted on one structural break where it is endogenously categorized from the dataset to lessen data mining issues. ${ }^{3}$

Table 4. Descriptive statistics after logarithm transformation.

\begin{tabular}{c|c|c|c|c|c}
\hline Descriptive Stats. & $\boldsymbol{L Y}$ & $\boldsymbol{L H}$ & $\boldsymbol{L N R E}$ & $\boldsymbol{L K}$ & $\boldsymbol{L L}$ \\
\hline Mean & 8.715 & 12.446 & 14.687 & 7.359 & -0.910 \\
\hline Std. Deviation & 0.349 & 0.229 & 0.505 & 0.398 & 0.057 \\
\hline Max & 9.260 & 13.051 & 15.350 & 7.937 & -0.751 \\
\hline Min & 8.179 & 12.113 & 13.916 & 6.509 & -0.984 \\
\hline Kurtosis & 1.685 & 3.585 & 1.560 & 2.444 & 3.967 \\
\hline Skewness & -0.1928 & 1.0305 & -0.229 & -0.585 & 1.254 \\
\hline Jarque-Bera & 0.078 & 0.191 & 2.562 & 0.185 & 0.300 \\
\hline
\end{tabular}

\footnotetext{
${ }^{3}$ ZA single structural break test is applied to indicate any existence of an unidentified structural break in the time series since the series applied in the analysis depend on several unpredictable events, (e.g. energy-affiliated policies, financial turmoil or other federal policy enactment). Without the application of the ZA test, the actual fluctuation in the level of time series (where series are integrated at zero order) in a certain time period may be unknown. Thus, the structural break approach in the unit root test can be applied to examine in which time period the structural break exists. Then, the presence of fluctuation in the series can be managed easily by using the ZA stationarity test. Another reason to apply a stationarity test in the appearance of breaks is the fluctuation of the data series, which is largely linked with the long-term association within the $\mathrm{I}(\mathrm{O})$ process. If the researcher fails to capture the integrational properties of the series, the long-term behaviour between the series may not be accurately forecast.
} 
Table 5. Correlation matrix and VIF after logarithm transformation.

\begin{tabular}{|c|c|c|c|c|c|}
\hline Variable & $L Y$ & LH & $L N R E$ & $L K$ & $L L$ \\
\hline$L Y$ & 1.000 & & & & \\
\hline LH & 0.609 & 1.000 & & & \\
\hline LNRE & 0.149 & -0.227 & 1.000 & & \\
\hline$L K$ & 0.855 & 0.518 & 0.122 & 1.000 & \\
\hline$L L$ & 0.874 & 0.733 & -0.072 & 0.713 & 1.00 \\
\hline VIF & - & 2.683 & 2.052 & 2.282 & 4.246 \\
\hline $1 / \mathrm{VIF}$ & - & 0.431 & 0.868 & 0.459 & 0.311 \\
\hline
\end{tabular}

\subsection{Cointegration Tests}

Previous research applied the multivariate framework to analyze a connection between energy and economic growth established proof of multiple cointegration behavior, e.g. Apergis \& Payne, 2010; Apergis \& Payne, 2009; Sadorsky, 2009a, 2009b. In order to address the inadequacy of this approach, Johansen (1988); Johansen and Juselius (1990) presented another long-term behavior test, starting with an unrestricted vector autoregressive model (VAR). Cointegration by Johansen shows that the vector of the variables $(X \times 1)$ at time $t$ depends on the vector of historical variables. The cointegration is specified as follows:

$$
\Delta X_{\mathrm{t}}=\Pi X_{\mathrm{t}-1} \sum_{i=1}^{k-1} \Gamma_{i} \Delta X_{\mathrm{t}-1}+\tau D_{\mathrm{t}}+\varepsilon_{\mathrm{t}}
$$

In equation $3, \Delta$ refers to the difference operator; $X_{t}$ refers to vector $4 \times 1$ of non-stationary variables of economic growth, hydroelectricity generation, capital and labor which were incorporated into I(1) series; Г's are regression coefficients for $4 \times 4$ matrices to be measured; $\Pi$ is the long-term for $4 \times 4$ parameter matrices; $D$ is a vector $4 \times 1$ of constant and trend terms; and $\varepsilon$ is a vector $4 \times 1$ of disturbance that adhered to the Gaussian white noise process with constant variance and zero mean. If $\Delta X_{t} \sim I(0)$, then $\Pi$ will be a zero matrix excluding when a linear combination of $X_{\mathrm{t}}$ is stationary. This technique confirms the rejection of the reduced rank $(r)$ of $\Pi$ matrices, which are estimated from an unrestricted VAR. The approaches in checking the reduced $r$ of matrices $\Pi$ are trace statistics and maximum eigenvalue, which is specified as follows: $\lambda_{\text {trace }}=-T \sum_{i=\gamma+1}^{k} \ln \left(1-\hat{\lambda}_{i}^{2}\right)$

$$
\lambda_{\max }(r, r+1)=-T \ln \left(1-\lambda_{r+1}\right)
$$


In equation $4, \lambda_{i}$ refers to the estimated order eigenvalue attained from the assessed matrix and $\mathrm{T}$ refers to the number of existing observations after lag adjustment. Meanwhile, the trace statistics $\left(\lambda_{\text {trace }}\right)$ in equation 5 measures the null hypothesis that the cointegrating vector $(r)$ is less than or equal to $r$ against a general alternative. Instead, the maximum eigenvalue $\left(\lambda_{\max }\right)$ calculates the null hypothesis of $\mathrm{r}$ cointegrating vectors against the alternative hypothesis of $r+1$ cointegrating vectors.

Besides the Johansen cointegration approach, this study also utilizes the ARDL bounds technique introduced by Pesaran et al. (2001) with the presence of structural breaks, subsequent to the recent work by Shahbaz, Hye, Tiwari, and Leitão (2013). The advantage of ARDL compared to other conventional cointegration tests is that it allows us to better execute statistically using a smaller sample, which makes it suitable to be implemented in the case of Malaysia (33 years). Conversely, the ARDL approach can be utilized whether the series are integrated at $\mathrm{I}(0), \mathrm{I}(1)$ or at a mixed order, since the test does not enforce a limit whereby all the series must be stationary in the same process. Next, the method provides unbiased long-term evaluations and provides legitimate t-statistics, although there is endogeneity in the explanatory variables.

The ARDL approach is in accordance with the standard log-linear functional model with the unrestricted error correction mechanism (UECM), which requires applying the lagged and contemporaneous values of the explanatory variables and the lags of the regression. An ARDL integrates the short-term relationship with the long-term relationship by not separating every long-term detail. It can be formulated in equations 6-10 as follows:

$$
\begin{aligned}
& \Delta L Y_{\mathrm{t}}=\beta_{y 0}+\gamma_{D} D+\theta_{y} T+\sum_{\mathrm{i}=1}^{p} \alpha_{y \mathrm{i}} \Delta L Y_{\mathrm{t}-\mathrm{i}}+\sum_{j=0}^{\mathrm{q}} \delta_{y \mathrm{i}} \Delta L H_{\mathrm{t}-j}+\sum_{k=0}^{r} \pi_{y i} \Delta L N R E_{\mathrm{t}-k}+\sum_{\mathrm{i}=0}^{s} \vartheta_{y \mathrm{i}} \Delta L L_{\mathrm{t}-\mathrm{i}}+\sum_{\mathrm{m}=0}^{v} \tau_{y \mathrm{i}} \Delta L K_{\mathrm{t}-\mathrm{m}} \\
& +\emptyset_{y 1} L Y_{t-1}+\emptyset_{y 2} L H_{t-1}+\emptyset_{y 2} L N R E_{t-1}+\emptyset_{y 4} L L_{t-1}+\emptyset_{y 5} L K_{t-1}+\varepsilon_{1 t} \\
& \Delta L H_{\mathrm{t}}=\beta_{\mathrm{h} 0}+\gamma_{0} D+\theta_{\mathrm{h}} T+\sum_{\mathrm{i}=1}^{\mathrm{p}} \alpha_{\mathrm{hi}} \Delta L H_{\mathrm{t}-\mathrm{i}}+\sum_{j=0}^{\mathrm{q}} \delta_{\mathrm{hi}} \Delta L Y_{\mathrm{t}-\mathrm{j}}+\sum_{\mathrm{k}=0}^{r} \pi_{\mathrm{hi}} \Delta L N R E_{\mathrm{t}-\mathrm{k}}+\sum_{\mathrm{i}=0}^{s} \vartheta_{\mathrm{hi}} \Delta L L_{\mathrm{t}-\mathrm{i}}+\sum_{\mathrm{m}=0}^{w} \tau_{\mathrm{hi}} \Delta L K_{\mathrm{t}-\mathrm{m}} \\
& +\emptyset_{h 1} L Y_{t-1}+\emptyset_{h 2} L H_{t-1}+\emptyset_{h 3} L N R E_{t-1}+\emptyset_{h 4} L L_{t-1}+\emptyset_{h 5} L K_{t-1}+\varepsilon_{2 t} \\
& \Delta L N R E_{\mathrm{t}}=\beta_{\text {nve }}+\gamma_{D} D+\theta_{\text {nve }} T+\sum_{\mathrm{i}=1}^{p} \alpha_{\text {nvei }} \Delta L N R E_{\mathrm{t}-\mathrm{i}}+\sum_{j=0}^{\mathrm{q}} \delta_{\text {nvei }} \Delta L Y_{\mathrm{t}-\mathrm{j}}+\sum_{k=0}^{r} \pi_{\text {nvei }} \Delta L H_{\mathrm{t}-\mathrm{k}}+\sum_{\mathrm{i}=0}^{s} \vartheta_{\text {nvei }} \Delta L L_{\mathrm{t}-1} \\
& +\sum_{m=0}^{D} \tau_{n v e i} \Delta L K_{t-m}+\emptyset_{n v e 1} L Y_{t-1}+\emptyset_{n v e 2} L H_{t-1}+\emptyset_{n v e a} L N R E_{t-1}+\emptyset_{n v e 4} L L_{t-1}+\emptyset_{n v e 5} L K_{t-1} \\
& +\varepsilon_{a t}
\end{aligned}
$$

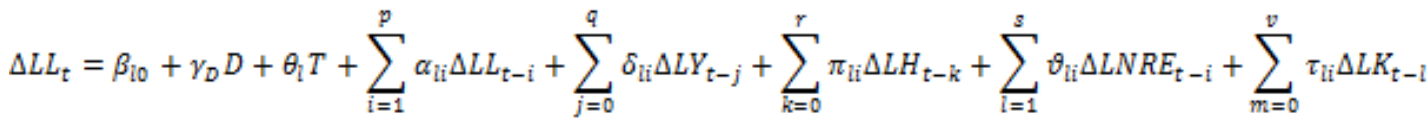

$$
\begin{aligned}
& +\emptyset_{i 1} L Y_{t-1}+\emptyset_{i 2} L H_{t-1}+\emptyset_{l a} L N R E_{t-1}+\emptyset_{l 4} L L_{t-1}+\emptyset_{l 5} L K_{t-1}+\varepsilon_{4 t}
\end{aligned}
$$




$$
\begin{aligned}
& \Delta L K_{\mathrm{t}}=\beta_{\mathrm{k} 0}+\gamma_{D} D+\theta_{k} T+\sum_{\mathrm{i}=1}^{p} \alpha_{\mathrm{ki}} \Delta L K_{\mathrm{t}-\mathrm{i}}+\sum_{j=0}^{q} \delta_{\mathrm{ki}} \Delta L Y_{\mathrm{t}-\mathrm{j}}+\sum_{k=0}^{r} \pi_{\mathrm{ki}} \Delta L H_{\mathrm{t}-k}+\sum_{\mathrm{i}=0}^{g} \vartheta \Delta L N R E_{\mathrm{t}-\mathrm{k}}+\sum_{\mathrm{m}=0}^{v} \tau_{k \mathrm{ki}} \Delta L L_{\mathrm{t}-\mathbb{1}} \\
& +\emptyset_{k 1} L Y_{t-1}+\emptyset_{k 2} L H_{t-1}+\emptyset_{k a} L N R E_{t-1}+\emptyset_{k 4} L L_{t-1}+\emptyset_{k 5} L K_{t-1}+\varepsilon_{5 t}
\end{aligned}
$$

The calculated F-statistics are :

\section{$F_{Y}(Y / H, N R E, L, K), F_{H}(H / Y, N R E, L, K), F_{N R E}(L / N R E, H, L, K) \quad F_{L}(L / Y, H, N R E, K)$ and $F_{K}(K / Y, H, N R E, L)$.}

The conclusion of any existence of cointegration between the variables is completed using the asymptotic critical values of lower critical bound and upper critical bound. The conclusion of any existence of cointegration between the variables is completed using the asymptotic critical values of lower critical bound and upper critical bound by the Narayan (2005) critical values for small sample sizes. The null hypothesis of no cointegration cannot be rejected if the F-statistics are smaller than the critical bound of $\mathrm{I}(0)$. Comparably, the null hypothesis of no cointegration can be rejected if the F-statistics are larger than the upper critical bound of $\mathrm{I}(1)$. However, the cointegration result is inconclusive if the calculated F-statistics are between the upper and lower critical bounds.

\subsection{Granger Causality}

This study applies VECM to scrutinize the presence of a causal association between hydroelectricity generation, real output, labor, and capital. VECM Granger causality is capable of capturing short-term causality grounded on the significance of F-statistics and long-term causality based on the lagged error correction term (ECT) between the analyzed variables. The VECM framework proposed by Engle and Granger (1987) can be specified as follows:

$$
\begin{aligned}
& \Delta L Y_{\mathrm{t}}=c_{10}+\omega_{11} D+\sum_{\mathrm{i}=1}^{\mathrm{p}} \alpha_{12} \Delta L Y_{\mathrm{t}-\mathrm{i}}+\sum_{j=0}^{q} \delta_{1 \mathrm{a}} \Delta L H_{\mathrm{t}-\mathrm{j}}+\sum_{k=0}^{p} \pi_{14} \Delta L N R E_{\mathrm{t}-\mathrm{k}}+\sum_{\mathrm{i}=0}^{g} \tau_{15} \Delta L L_{\mathrm{t}-\mathrm{i}}+\sum_{\mathrm{m}=0}^{\mathrm{w}} \vartheta_{16} \Delta L K_{\mathrm{t}-\mathrm{m}} \\
& +\delta_{17} E C T_{t-1}+\varepsilon_{1 t} \\
& \Delta L H_{\mathrm{t}}=c_{20}+\omega_{21} D+\sum_{\mathrm{i}=1}^{\mathrm{p}} \alpha_{22} \Delta L H_{\mathrm{t}-\mathrm{i}}+\sum_{j=0}^{\mathrm{q}} \delta_{2 \mathrm{a}} \Delta L Y_{\mathrm{t}-j}+\sum_{k=0}^{r} \pi_{24} \Delta L N R E_{\mathrm{t}-\mathrm{k}}+\sum_{\mathrm{i}=0}^{s} \tau_{25} \Delta L L_{\mathrm{t}-\mathrm{i}}+\sum_{\mathrm{m}=0}^{\mathrm{D}} \vartheta_{26} \Delta L k 11 \\
& +\delta_{27} E C T_{t-1}+\varepsilon_{2 t} \\
& \Delta L N R E_{\mathrm{t}}=c_{\mathrm{a} 0}+\omega_{\mathrm{a} 1} D+\sum_{\mathrm{i}=1}^{p} \alpha_{\mathrm{a} 2} \Delta L N R E_{\mathrm{t}-\mathrm{i}}+\sum_{j=0}^{\mathrm{q}} \delta_{\mathrm{ag}} \Delta L Y_{\mathrm{t}-\mathrm{j}}+\sum_{\mathrm{k}=0}^{p} \pi_{\mathrm{a} 4} \Delta L H_{\mathrm{t}-\mathrm{k}} \quad+\sum_{\mathrm{i}=0}^{s} \tau_{\mathrm{a} 5} \Delta L L_{\mathrm{t}-\mathrm{i}} \\
& +\sum_{m=0}^{W} \vartheta_{a b} \Delta L K_{t-m}+\delta_{a z} E C T_{t-1}+\varepsilon_{a t}
\end{aligned}
$$




$$
\begin{aligned}
& \Delta L L_{t}=c_{40}+\omega_{41} D+\sum_{i=1}^{p} a_{42} \Delta L L_{t-i}+\sum_{j=0}^{q} \delta_{43} \Delta L Y_{t-j}+\sum_{k=0}^{r} \pi_{44} \Delta L H_{t-k}+\sum_{i=1}^{s} \tau_{45} \Delta L N R E_{t-1}+\sum_{m=0}^{v} \vartheta_{46} \Delta L K_{t-m} \\
& +\delta_{47} E C T_{t-1}+\varepsilon_{4 t} \\
& \Delta L K_{t}=c_{50}+\omega_{51} D+\sum_{i=1}^{p} a_{52} \Delta L K_{t-i}+\sum_{j=0}^{q} \delta_{58} \Delta L Y_{t-j}+\sum_{k=0}^{r} \pi_{54} \Delta L H_{t-k}+\sum_{i=1}^{s} \tau_{55} \Delta L N R E_{t-1}+\sum_{m=0}^{v} \vartheta_{56} \Delta L L_{t-m} \\
& +\delta_{57} E C T_{t-1}+\varepsilon_{5 t}
\end{aligned}
$$

where $\Delta$ refers to the first difference operator; $c$ refers to the constant parameter; $D$ refers to the dummy variable that signifies value of one after the existence of a break and zero otherwise; $L Y_{s} L H, L N R E, L K, L L$ are the natural logarithms of real income, hydroelectricity and non-renewable energy generation, labor, and capital respectively; $p, q, r_{v}, s_{v} v$ refer to the optimal lag lengths designated based on the AIC; $E C T_{t-1}$ is the error correction term obtained from long-term equilibrium association; $\varepsilon$ is the error term; $\alpha, \delta, \pi, \tau, \vartheta$ are the coefficients of the lagged explanatory variables that represent the short-term effects of the explanatory variables on the dependent variables. Referring to equations 11-15, long-term causality is established based on the statistical significance of the Wald statistics associated with the $E C T_{t-1}$. Instead, from equations 11-15, short-term causality is calculated based on the statistical significance of the sum of the lagged differences connected with the right-hand side variables through partial Wald statistics.

\section{RESULTS}

The stationarity results in Table 6 show that all series are non-stationary in level, however, they become stationary in the first difference regardless of intercept, or intercept and trend. However, the approximation of the results of the KPSS test is varied, e.g. some series are stationary in level and some series have unit roots in level. Accordingly, the ADF, PP and KPSS examinations provide ambiguous results since the stationary nature of all variables is inconclusive.

Table 6. Stationarity test.

\begin{tabular}{c|c|c|c|c|c|c}
\hline Variables & \multicolumn{2}{|c|}{ ADF } & \multicolumn{2}{c|}{ PP } & \multicolumn{2}{c}{ KPSS } \\
\hline INTERCEPT & Level & First diff. & Level & $\begin{array}{c}\text { First } \\
\text { diff. }\end{array}$ & $\begin{array}{c}\text { Level } \\
\begin{array}{c}\text { First } \\
\text { diff. }\end{array}\end{array}$ \\
\hline $\boldsymbol{L Y}$ & $-0.372(1)$ & $-6.489^{\mathrm{a}}(0)$ & -0.565 & $-6.440^{\mathrm{a}}$ & $0.663^{\mathrm{b}}$ & 0.086 \\
\hline $\boldsymbol{L H}$ & $-1.325(0)$ & $-4.826^{\mathrm{a}}(2)$ & -1.205 & $-6.933^{\mathrm{a}}$ & $0.561^{\mathrm{b}}$ & $0.500^{\mathrm{b}}$ \\
\hline $\boldsymbol{L N R \boldsymbol { E }}$ & $-0.852(2)$ & $-4.713^{\mathrm{a}}(7)$ & -1.338 & $-7.616^{\mathrm{a}}$ & $0.643^{\mathrm{b}}$ & 0.272 \\
\hline $\boldsymbol{L K}$ & $-1.106(0)$ & $-4.904^{\mathrm{a}}(0)$ & -1.151 & $-4.904^{\mathrm{a}}$ & $0.534^{\mathrm{a}}$ & 0.075 \\
\hline $\boldsymbol{L L}$ & $1.090(1)$ & $-4.219^{\mathrm{a}}(8)$ & -0.006 & $-8.819^{\mathrm{a}}$ & $0.718^{\mathrm{b}}$ & 0.095 \\
\hline
\end{tabular}




\begin{tabular}{c|c|c|c|c|c|c}
\hline $\begin{array}{c}\text { INTERCEPT } \\
\text { AND TREND }\end{array}$ & & & & & \\
\hline $\boldsymbol{L Y}$ & $-1.977(\mathrm{O})$ & $-6.381^{\mathrm{a}}(\mathrm{O})$ & -2.155 & $-6.339^{\mathrm{a}}$ & $0.135^{\mathrm{c}}$ & 0.075 \\
\hline $\boldsymbol{L H}$ & $-1.502(8)$ & $-4.861^{\mathrm{a}}(2)$ & -2.089 & $-7.877^{\mathrm{a}}$ & 0.122 & $0.500^{\mathrm{b}}$ \\
\hline $\boldsymbol{L N R \boldsymbol { E }}$ & $-2.524(2)$ & $-16.304^{\mathrm{a}}$ & $-2.909^{\mathrm{a}}$ & $-7.795^{\mathrm{a}}$ & 0.088 & $0.271^{\mathrm{b}}$ \\
\hline $\boldsymbol{L K}$ & $-1.838(0)$ & $-4.832^{\mathrm{a}}(0)$ & -2.059 & $-4.832^{\mathrm{a}}$ & $0.095^{\mathrm{c}}$ & 0.081 \\
\hline $\boldsymbol{L L}$ & $3.292(8)$ & $-9.354^{\mathrm{a}}(\mathrm{O})$ & -2.307 & $-9.362^{\mathrm{a}}$ & $0.113^{\mathrm{c}}$ & $0.115^{\mathrm{b}}$ \\
\hline
\end{tabular}

(2) Estimates in parentheses indicate the optimal lag length as selected based on AIC (Akaike, 1969).

This study conducted a ZA test once more to improve the validity of a stationarity hypothesis in the variables and cater to the existence of a structural break in the series. Table 7 demonstrates the results of the ZA test and reports that structural breaks occurred in 1999 and 2002 in the series of output, hydroelectricity generation, and capital. This study also identified that the labor series had a structural break in 2009. The inclusion of the nonrenewable energy variable displays that the series experienced a structural break in 1992. The significant deduction from the completed ZA unit root tests is that all the series are incorporated at I(1) process by successfully capturing the true inconstancy in the level series data when the stationarity assessments were analyzed.

Table 7. ZA stationarity test.

\begin{tabular}{|c|c|c|c|c|c|c|}
\hline Variables & Level & Break & Lag Length & First Diff. & Break & Lag Length \\
\hline$L Y$ & -4.223 & 1993 & 3 & $-6.601^{a}$ & 1999 & $\mathrm{O}$ \\
\hline LH & -4.347 & 2001 & 1 & $-5.994^{\mathrm{a}}$ & 2002 & 2 \\
\hline$L N R E$ & -4.428 & 1994 & 1 & $-9.098^{a}$ & 1992 & 1 \\
\hline$L K$ & -3.566 & 1999 & $\mathrm{O}$ & $-6.005^{\mathrm{a}}$ & 1999 & $\mathrm{O}$ \\
\hline$L L$ & -4.743 & 2008 & 1 & $-10.984^{a}$ & 2009 & 2 \\
\hline
\end{tabular}

Since the Johansen cointegration test is only valid when the non-stationary series is integrated with $\mathrm{I}(1)$ process, the long-term analyses are initially analyzed using this test. Estimation through a cointegration approach requires the optimum lag length preference at the first phase. Table 8 shows that the AIC prefers four lags that offer better residual characteristics for the model against lesser lags found in SIC and LR. Table 9 depicts the specification tests for the linearized model in equation 2 with the integration of non-renewables, and demonstrates that non-normality, autocorrelation, and heteroscedasticity have no issues.

Table 8. VAR lag length order criteria.

\begin{tabular}{c|c|c|c}
\hline Lag & Lr & Aic & Sic \\
\hline 0 & NA & -3.283 & -3.049 \\
\hline 1 & 176.879 & -8.986 & -7.585 \\
\hline 2 & 45.149 & -9.696 & -7.127 \\
\hline 3 & 29.830 & -10.160 & -6.423 \\
\hline 4 & $38.245^{*}$ & $-12.743^{*}$ & $-7.839^{*}$ \\
\hline
\end{tabular}

Note: Specifies the lag length order by the criterion. 
Table 9. Specification test results

\begin{tabular}{c|c|c|c|c}
\hline Models & $\begin{array}{c}\text { Lagrange } \\
\text { Multiplier }\end{array}$ & $\begin{array}{c}\text { White } \\
\text { Heteroscedasticity }\end{array}$ & Jarque-Bera & Ar-Polynomial \\
\hline $\boldsymbol{Y} \mid \boldsymbol{H}_{s} \boldsymbol{N R E _ { s } \boldsymbol { K } _ { s } \boldsymbol { L }}$ & $1.318(0.205)$ & $311.220(0.316)$ & $9.292(0.300)$ & Inside \\
\hline
\end{tabular}

Note: (1) Jarque-Bera test null is residual normality.

(2) Autocorrelation Lagrange multiplier test is null is no serial correlation up to selected lag.

(3) White heteroscedasticity test includes cross terms, and the null is heteroscedasticity.

(4) Inverse roots of the characteristic AR (auto-regressive) polynomial reveal that all roots lie inside the unit circle

(5) The p-value is in brackets.

Results from the Johansen cointegration approach illustrated in Table 10 specify that a long-term association occurs between real output, hydroelectricity and fossil fuel generation, capital, and labor. According to the recommended lag length, the null hypothesis of no cointegration is rejected at a $5 \%$ significance level by the trace and maximum eigenvalue statistics with one cointegrating relation. However, a weakness of the Johansen approach is that it does not account for any probability of fluctuation occurring in the time series data. Additionally, the results suffer from a small sample bias. Hence, the ARDL bound test cointegration approach is executed in the existence of structural breaks comparable to the earlier analysis.

Table 10. Johansen cointegration test results.

\begin{tabular}{c|c|c|c|c}
\hline \multicolumn{5}{c}{ TRACE } \\
\hline HO & Eigenvalue & Statistics & 5\% Critical value & P-value $^{* *}$ \\
\hline $\mathrm{R}=\mathrm{O}^{*}$ & 0.759 & 106.550 & 84.378 & 0.002 \\
\hline $\mathrm{R} \leq 1^{*}$ & 0.613 & 60.931 & 60.086 & 0.086 \\
\hline $\mathrm{HO}$ & MAXIMUM EIGENVALUE & P-value \\
\hline $\mathrm{R}=\mathrm{O}^{*}$ & Eigenvalue & Statistics & $10 \%$ Critical value & 0.005 \\
\hline $\mathrm{R} \leq 1$ & 0.759 & 45.619 & 35.581 & O.081 \\
\hline
\end{tabular}

Table 11 details the findings of the ARDL bound approach, which reported the presence of cointegration since the computed F-statistics are greater than the upper critical bound values stipulated by Narayan (2005) for small sample sizes based on unrestricted intercept and trend. The results indicate that the ARDL bound approach corroborates the long-term relationship between the series when real output, hydroelectricity generation, nonrenewables, labor, and capital are treated as endogenous variables.

Based on the long-term impact in the ARDL cointegration approach, Table 11 shows that all the coefficient estimates become smaller compared to the main findings. The influence of non-renewable energy in the production function demonstrated that fossil fuels promote economic development in Malaysia, but to a slighter extent compared to the hydroelectric industry. In detail, a $1 \%$ increase in hydroelectricity generation leads to a $0.12 \%$ increase in real output. However, fossil fuels only account for a $0.030 \%$ increase in economic growth. Labor was identified to have a negative influence on economic growth, while capital demonstrated a positive long-term relationship with economic growth. Furthermore, the estimated equation includes the dummy variable in 1999 to account for the sudden change in the time series, as indicated by the ZA unit root test, for a long-term marginal influence on output performance. This result established the significance of a structural break in influencing Malaysian economic development in the specific period of study. This finding suggests that the recovery from the Asian financial crisis is critical in influencing the economic expansion of the country.

Similarly, in Table 11, the short-term impact reveals that a $1 \%$ increase in hydroelectricity generation is positive and significant to real output by $0.198 \%$, and its impact is slightly higher than in the long term. Furthermore, fossil fuels positively influence economic growth in the short term despite it having a smaller influence compared to hydroelectricity generation. This finding suggests that hydroelectric investment had a positive impact on the economic performance in Malaysia during the sample period compared to fossil fuel usage. 
Table 11 also depicts that the ECT coefficient is significant and negative, indicating that $75.1 \%$ of the divergence from long-term equilibrium is resolved in a one-year period. The estimated ARDL model was also tested with the necessary diagnostic test, and it confirmed that the model does not exhibit any presence of non-normality, heteroscedasticity, or autocorrelation in the residuals.

Table 11. ARDL estimation model for Equation 2.

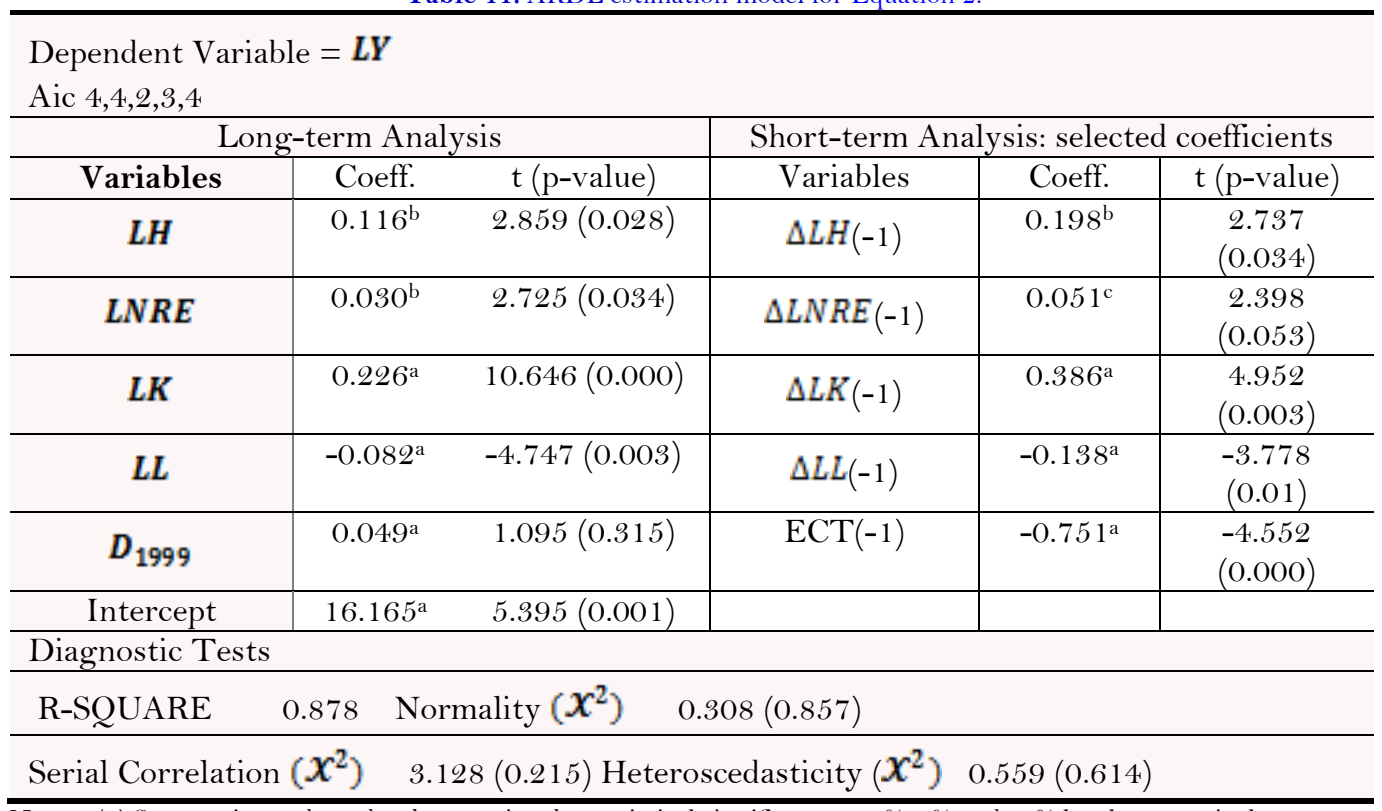

Notes: (1) Superscripts a, b, and c characterize the statistical significance at $1 \%, 5 \%$ and $10 \%$ levels respectively.

(2) Numbers in parentheses in the long-term and short-term analyses are standard errors.

(3) The lag length is selected based on the AIC.

(4) Numbers in parenthesis in the diagnostic tests are probability values.

Next, the charts of CUSUM and CUSUMQ with a structural break in Figure 1 reveal that the estimated ARDL coefficient and specifications are consistent during the period because the diagram plots fall inside $5 \%$ significance level boundaries. This finding indicates that the model estimations are constructively stable during the observation of the study with the inclusion of the non-renewables variable similar to the previous analysis.

Table 12 presents VECM causality results when non-renewable energy was used as a supplementary variable in the production function model. Beginning with equation 11, the results show that hydroelectricity and labor are the only factors that Granger found that cause real output in the short term. Meanwhile, in equation 12, real output is the only factor that displays a short-term causation on hydroelectricity generation. The inclusion of nonrenewable energy as an extra variable in equation 13 reported that real output and labor have negative short-term causation on the usage of fossil fuels. In equation 14, hydroelectricity and fossil fuels are factors that Granger cause the labor in the short term. The result suggests that investment in conventional and alternative energy requires a sufficient amount of labor to execute the energy project. Last, concerning equation 15 for capital, only real output has short-term causation on the establishment of physical capital for the country during the sample period. 

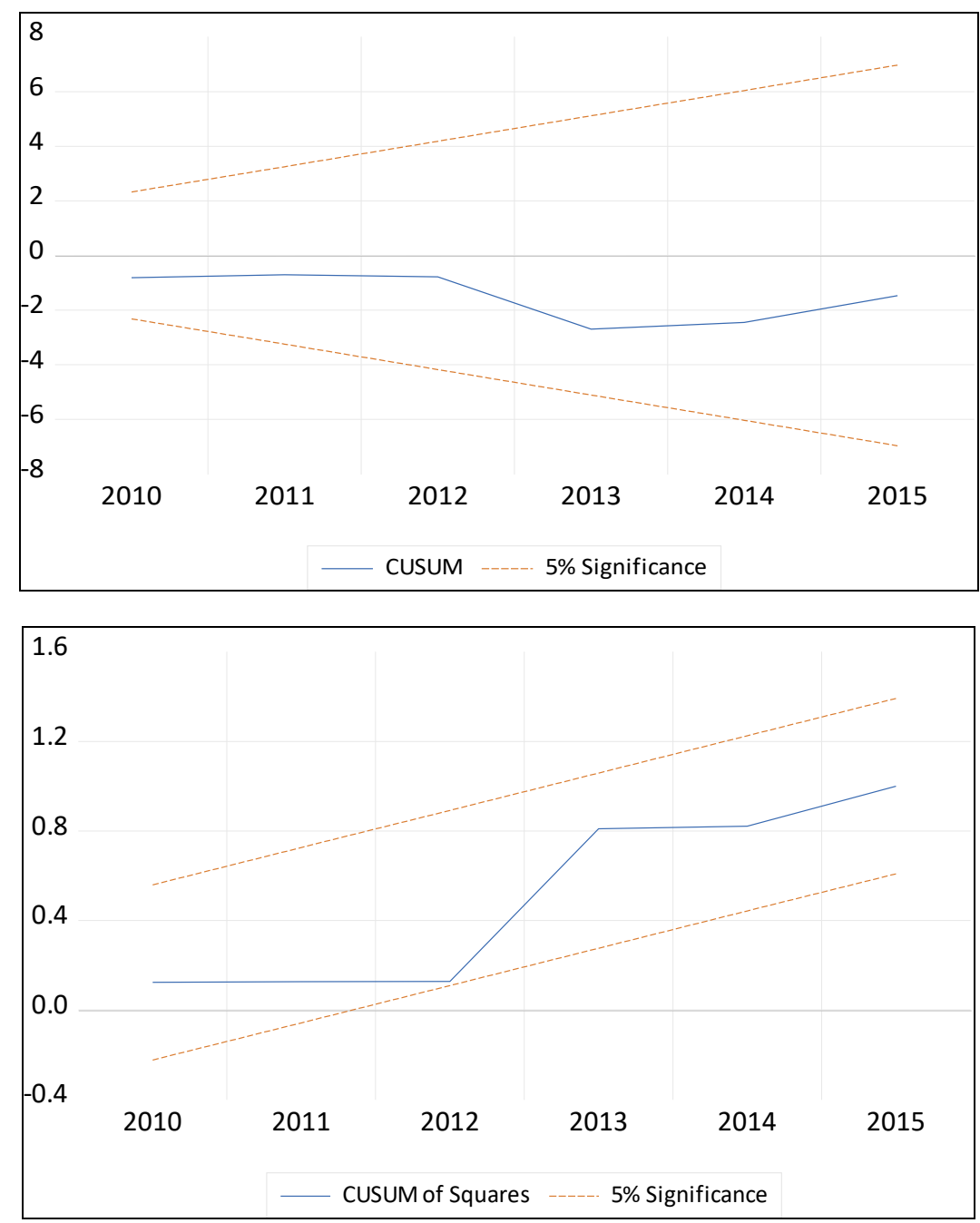

Figure 1. CUSUM and CUSUMSQ stability tests.

Table 12 also depicted the adjustment speed, responding to the shocks towards long-term equilibrium concerning long-term causality links between the variables. The coefficient of the ECT is negative and significant across equations 11-15, which supports the idea that the hydroelectric sector is the driving factor in the renewable energy-GDP relationship. The estimated VECM Granger causality was also tested with the necessary diagnostic test, and it was confirmed that the model does not exhibit any presence of non-normality, heteroscedasticity, or autocorrelation in the residuals.

\section{DISCUSSION}

The findings in this research indicate that the existence of long-term behavior between the variables and hydroelectricity can be considered as an essential factor, as well as labor and capital, on output performance. Hence, it is concluded that conventional and renewable energy generation are positively associated with economic growth in Malaysia. Nevertheless, since some of the country's fossil fuel demand is met by importing from a neighboring country, namely Indonesia, the country should diversify its energy sources by investing in alternative energy, especially in the hydroelectric sector, which is likely to promote sustainable growth for the country (IEA, 2015). This can be endorsed by the findings obtained by the ARDL long-term and short-term estimations, whereby fossil fuels encourage output level in Malaysia despite the lesser extent compared to the hydroelectric industry. The longterm linkage between renewable energy and economic growth determined in this study does not align with the 
study by Dogan (2015); Dogan (2016) who identified that renewable energy damages the output level in Turkey in the long term.

Concerning the direction of causality, the outcomes of bidirectional causality in the short term and long term between real GDP and hydroelectricity generation confirm the feedback hypothesis, inferring that a more significant generation of hydroelectricity contributes to growth in economic production and vice versa. Hydroelectricity can be regarded as a capital-intensive project, which requires high initial outlay before the project can commence and requires ongoing maintenance costs. Therefore, a higher level of output growth is likely to be able to handle the costs associated with hydroelectric investments. Likewise, the results emphasize the importance of the development of an energy enactment policy and the efficient provision of hydroelectricity generation to encourage output performance. It can be proven that hydroelectricity is a source that does not deplete in energy production and can be implemented on a large scale in Malaysia. Thus, any energy conservation strategies could harm economic performance if the strategies enacted create a reduction in hydroelectric sources. Accordingly, given the evidence of causality, the deployment of hydroelectricity projects is beneficial for the country; substituting fossil fuel resources with hydroelectricity should be a practical approach, as this will reduce fossil fuel dependency and strengthen the energy security in the country. The findings of bidirectional causality between real output and hydroelectricity generation are persistent with the findings obtained by Ohler and Fetters (2014) and Solarin and Ozturk (2015a). Ohler and Fetters (2014) found that hydroelectricity exhibits a bidirectional association with output across 20 OECD countries. Solarin and Ozturk (2015b) discovered that hydroelectric consumption has a long-term causality on economic performance in Latin American nations. However, this study expands prior literature by illuminating the feedback hypothesis between hydroelectricity and economic growth, indicating a bidirectional causality according to a time series analysis.

A noteworthy finding identified by this study is the negative causal relationship between non-renewable energy and real output in the short term. The finding is inconsistent with those obtained by several studies, (e.g. (Al-Mulali et al., 2014; Dogan, 2015; Dogan, \& Seker, 2016; Ohler \& Fetters, 2014; Sadorsky, 2009b)), that found that fossil fuels play an essential role in economic expansion along with alternative energy. The inconsistent result found in this study might be due to a dependence on conventional energy, which could be detrimental to economic growth. Hence, a nation can profit if energy diversification is executed nationally, specifically if the nation's present setting has initiated fossil fuel imports to fulfil energy demand.

Furthermore, it was revealed that unidirectional causality was found between labor and hydroelectricity in the short term, supporting the growth hypotheses. This can be explained by the fact that hydroelectric plants are complex construction projects that require large amounts of skilled labor. Accordingly, the successful implementation of energy projects requires sufficient labor to be available at the beginning of the project. Similarly, the inauguration of hydroelectric plants will be beneficial to local people by creating job opportunities in the energy sector in addition to other sectors, such as transportation, fishing, and tourism. 


\begin{tabular}{|c|c|c|c|c|c|c|c|c|c|}
\hline \multirow[t]{2}{*}{$\begin{array}{l}\text { Dependent } \\
\text { variable }\end{array}$} & \multicolumn{4}{|c|}{$\begin{array}{l}\text { Short-term causality } \\
\text { (independent variables) }\end{array}$} & \multirow[b]{2}{*}{$\Delta L K$} & \multirow{2}{*}{$\begin{array}{c}\begin{array}{c}\text { Long- } \\
\text { term } \\
\text { causality }\end{array} \\
E C T_{t-1}\end{array}$} & \multicolumn{3}{|c|}{ Diagnostic tests } \\
\hline & $\Delta L Y$ & $\Delta L H$ & $\triangle L N R E$ & $\Delta L L$ & & & $\begin{array}{c}\text { Normality } \\
x^{2}(3)\end{array}$ & $\begin{array}{l}\text { Serial correlation } \\
\qquad x^{2}(3)\end{array}$ & $\begin{array}{c}\text { Heteroscedasticity } \\
x^{{ }^{2}}(3)\end{array}$ \\
\hline (2.26) $\Delta L Y$ & - & $\begin{array}{l}8.779 \\
(0.032) \\
{[0.08]^{\mathrm{c}}}\end{array}$ & $\begin{array}{c}1.955 \\
(-0.017) \\
{[0.226]}\end{array}$ & $\begin{array}{l}4.358 \\
(0.066) \\
{[0.081]^{\mathrm{c}}}\end{array}$ & $\begin{array}{c}1.699 \\
(0.119) \\
{[0.233]}\end{array}$ & $\begin{array}{c}-0.866 \\
{[0.040]^{\mathrm{b}}}\end{array}$ & $7.980[0.157]$ & $1.314[0.198]$ & $20.363[0.276]$ \\
\hline$(2.27) \Delta L H$ & $\begin{array}{c}5.534 \\
(2.831) \\
{[0.10]^{\mathrm{c}}}\end{array}$ & - & $\begin{array}{l}14.532 \\
(-0.009) \\
{[0.002]^{b}}\end{array}$ & $\begin{array}{c}2.582 \\
(0.135) \\
{[0.381]}\end{array}$ & $\begin{array}{c}3.471 \\
(-0.586) \\
{[0.120]}\end{array}$ & $\begin{array}{c}-0.406 \\
{[0.004]^{\mathrm{b}}}\end{array}$ & $5.611[0.346]$ & $0.685[0.833]$ & $396.953[0.208]$ \\
\hline (2.28) $\triangle L N R E$ & $\begin{array}{c}5.10 \\
(-0.240) \\
{[0.058]^{c}} \\
\end{array}$ & $\begin{array}{c}3.121 \\
(-1.263) \\
{[0.073]^{\mathrm{c}}} \\
\end{array}$ & - & $\begin{array}{c}0.365 \\
(-0.145) \\
{[0.712]^{\mathrm{a}}} \\
\end{array}$ & $\begin{array}{c}0.365 \\
(0.672) \\
{[0.609]}\end{array}$ & $\begin{array}{c}-0.226 \\
{[0.025]^{\mathrm{b}}}\end{array}$ & $5.701[0.325]$ & $0.333[0.847]$ & $15.806[0.999]$ \\
\hline (2.29) $\Delta L L$ & $\begin{array}{l}1.685 \\
(0.104) \\
{[0.679]}\end{array}$ & $\begin{array}{c}17.18 \\
(-0.216) \\
{[0.004]^{\mathrm{a}}}\end{array}$ & $\begin{array}{c}9.904 \\
(-0.036) \\
{[0.02]^{b}}\end{array}$ & - & $\begin{array}{c}1.717 \\
(-0.033) \\
{[0.527]}\end{array}$ & $\begin{array}{c}-0.773 \\
{[0.024]^{\mathrm{b}}}\end{array}$ & $1.223[0.542]$ & $3.331[0.189]$ & $15.946[0.773]$ \\
\hline (2.30) $\Delta L K$ & $\begin{array}{c}7.049 \\
(-4.111) \\
{[0.05]^{\mathrm{b}}}\end{array}$ & $\begin{array}{l}1.207 \\
(0.065) \\
{[0.848]}\end{array}$ & $\begin{array}{l}4.933 \\
(0.299) \\
{[0.177]}\end{array}$ & $\begin{array}{c}0.898 \\
(-0.651) \\
{[0.795]}\end{array}$ & - & $\begin{array}{c}-0.840 \\
{[0.040]^{\mathrm{b}}}\end{array}$ & $0.169[0.918]$ & $1.711[0.201]$ & $16.525[0.739]$ \\
\hline
\end{tabular}




\section{CONCLUSION}

This study investigated whether long-term behavior and causality existed between hydroelectric sources and output performance in Malaysia between 1982 and 2015. A production function model was employed in this study, and the author believes that this study is one of the first thorough methods to be used in Malaysia that includes hydroelectricity, capital, and labor. The ADF, PP and KPSS unit root tests were performed to determine the existence of non-stationarity in the series. The ZA unit root test was employed to consider the potential of an unknown fluctuation by capturing any occurrence of a structural break in the variables. The Johansen cointegration and ARDL bounds testing approaches were also employed to determine the presence of long-term behavior in the series, with the latter model integrating information regarding the existence of a single structural break in the time series data. Last, the VECM Granger causality with a structural break was conducted to examine the extent of the causality test.

The empirical evidence presented here indicates that both the Johansen cointegration and ARDL bound tests verified the occurrence of long-term behavior between the variables. After the cointegration presence had been validated, the ARDL model estimation revealed that hydroelectricity is a critical component of production to encourage long-term output growth. In addition, labor force is a vital component that stimulates economic development. The causality results in this study identified the existence of two-way causality between hydroelectricity generation and economic growth in the short term and long term. This finding implies that the development of greater electricity generation from hydroelectric sources will promote economic expansion and vice versa, which indicates significant and superior economic growth boost from hydroelectric generation in the short term and long term.

The findings of the feedback hypothesis warn against implementing environmental policies that obstruct energy supply from renewable sources because it is likely that it may harm the output performance. In the case of Malaysia, high dependence on energy imports to satisfy energy requirements may harm the output growth. Hence, the relevant stakeholders, especially policymakers, are encouraged to focus on minimizing dependence on external energy sources to enhance the supply security in this nation. Accordingly, authorities should consider prioritizing the development of local energy sources through the increase of hydroelectric capacity.

Aside from the feedback hypothesis between hydroelectricity and economic growth, the findings obtained in this study propose a negative growth hypothesis between real output and non-renewable energy. Consequently, the government should prioritize providing an adequate capital to boost the production of the energy industry that is related to the present stock of physical capital. Finally, the results in this study indicate a feedback hypothesis in the short term, and a growth hypothesis in the long term between labor and hydroelectric sources. Therefore, the most relevant strategy is to maximize the current labor supply needed to be made country-wide, given the positive role it plays in hydroelectric sources.

Funding: This study received no specific financial support.

Competing Interests: The authors declare that they have no competing interests.

Acknowledgement: The authors would like to convey the sincerest gratitude for the constructive feedback and recommendations from the editor in enhancing the composition of this article.

\section{REFERENCES}

Akaike, H. (1969). Fitting autoregressive models for regression. Annals of the Institute of Statistical Mathematics, 21, $243-247$.

Al-Mulali, U., Fereidouni, H. G., \& Lee, J. Y. (2014). Electricity consumption from renewable and non-renewable sources and economic growth: Evidence from Latin American countries. Renewable and Sustainable Energy Reviews, 30, $290-298$. Available at: https://doi.org/10.1016/j.rser.2013.10.006

Apergis, N., \& Payne, J. E. (2010). Renewable energy consumption and economic growth: Evidence from a panel of OECD countries. Energy Policy, 38(1), 656-660. Available at: https://doi.org/10.1016/j.enpol.2009.09.002. 
Apergis, N., \& Payne, J. E. (2009). Energy consumption and economic growth: Evidence from the commonwealth of independent states. Energy Economics, 31(5), 641-647. Available at: 10.1016/j.eneco.2009.01.011.

Apergis, N., \& Payne, J. E. (2011a). A dynamic panel study of economic development and the electricity consumption-growth nexus. Energy Economics, 33(5), 770-781. Available at: 10.1016/j.eneco.2010.12.018.

Apergis, N., \& Payne, J. E. (2011b). On the causal dynamics between renewable and non-renewable energy consumption and economic growth in developed and developing countries. Energy Systems, 2(3-4), 299-312. Available at: 10.1007/s12667-011-0037-6.

Apergis, N., \& Payne, J. E. (2011c). Renewable and non-renewable electricity consumption-growth nexus: Evidence from emerging market economies. Applied Energy, 88(12), 5226-5230. Available at: 10.1016/j.apenergy.2011.06.041.

Apergis, N., \& Payne, J. E. (2011d). The renewable energy consumption-growth nexus in Central America. Applied Energy, 88(1), 343-347. Available at: 10.1016/j.apenergy.2010.07.013.

Ariff, M., \& Abubakar, S. Y. (1999). The Malaysian financial crisis: Economic impact and recovery prospects. Developing Economies. Available at: 10.1111/j.1746-1049.1999.tbo0241.x.

Azam, M., Khan, A. Q., Bakhtyar, B., \& Emirullah, C. (2015). The causal relationship between energy consumption and economic growth in the ASEAN-5 countries. Renewable and Sustainable Energy Reviews, 47, 732-745. Available at: https://doi.org/10.1016/j.rser.2015.03.023.

Ben Jebli, M., \& Ben Youssef, S. (2015). The environmental Kuznets curve, economic growth, renewable and non-renewable energy, and trade in Tunisia. Renewable and Sustainable Energy Reviews. Elsevier, 47, 173-185. Available at: 10.1016/j.rser.2015.02.049.

Chontanawat, J., Hunt, L. C., \& Pierse, R. (2008). Does energy consumption cause economic growth?: Evidence from a systematic study of over 100 countries. Journal of Policy Modeling, 30(2), 209-220. Available at: https://doi.org/10.1016/j.jpolmod.2006.10.003.

Dickey, D., \& Fuller, W. A. (1979). Distribution of the estimators for time series regressions with a unit root. Journal of the American Statistical Association, 74(366), 427-431. Available at: https://doi.org/10.2307/2286348.

Dogan, E. (2015). The relationship between economic growth and electricity consumption from renewable and non-renewable sources: A study of Turkey. Renewable and Sustainable Energy Reviews, 52, 534-546. Available at: https://doi.org/10.1016/j.rser.2015.07.130.

Dogan, E. (2016). Analyzing the linkage between renewable and non-renewable energy consumption and economic growth by considering structural break in time-series data. Renewable Energy, 99, 1126-1136. Available at: 10.1016/j.renene.2016.07.078.

Dogan, E., \& Seker, F. (2016). The influence of real output, renewable and non-renewable energy, trade and financial development on carbon emissions in the top renewable energy countries. Renewable and Sustainable Energy Reviews, 60, 1074-1085. Available at: https://doi.org/10.1016/j.rser.2016.02.006.

Engle, R. F., \& Granger, C. W. J. (1987). Co-integration and error correction: Representation, estimation, and testing. Econometrica, 55(2), 251. Available at: 10.2307/1913236.

Granger, C., \& Newbold, P. (1974). Spurious regressions in econometrics. Journal of Econometrics, 2(2), 111-120. Available at: https://doi.org/10.1016/0304-4076(74)90034-7.

Gregory, A., \& Hansen, B. (1996). Residual based test and spatial price linkages in regional cattle markets. Journal of Econometrics, $70(1), 99-126$.

Hall, C., Tharakan, P., Hallock, J., Cleveland, C., \& Jefferson, M. (2003). Hydrocarbons and the evolution of human culture. Nature, 426(6964), 318-322. Available at: https://doi.org/10.1038/nature02 130.

Hatemi-J, A. (2012). Asymmetric causality tests with an application. Empirical Economics, 43(1), 447-456. Available at: https://doi.org/10.1007/s00181-011-0484-x.

IEA. (2015). International energy agency Southeast Asia energy outlook. Retrieved from: https://doi.org/10.1787/9789264285576-en. [Accessed 20 September 2019]. 
Asian Economic and Financial Review, 2020, 10(10): 1147-1168

IHA. (2015). International hydropower association '2015 hydropower status report. Retrieved from https://www.hydropower.org/sites/default/files/publications-

docs/2015\%20Hydropower\%20Status\%20Report\%20double\%20pages.pdf. [Accessed 20 September 2019].

IHA. (2016). International hydropower association '2016 hydropower status report. Retrieved from https://www.hydropower.org/sites/default/files/publications-

docs/2016\%20Hydropower\%20Status\%20Report 1.pdf. [Accessed 20 September 2019].

Ishak, S. R. (2014). KDNK S3 5.6\%, MyMetro. Retrieved from http://www.hmetro.com.my/node/9176.

Johansen, S., \& Mosconi, R. (2000). Cointegration analysis in the presence of structural breaks in the deterministic trend. Econometrics Journal, 3, 216-249.

Johansen, S. (1988). Statistical analysis of cointegration vectors. Journal of Economic Dynamics and Control, 12(2-3), $231-254$. Available at: https://doi.org/10.1016/0165-1889(88)90041-3.

Johansen, S., \& Juselius, K. (1990). Maximum likelihood estimation and inference on cointegration — with applications to the demand for money. Oxford Bulletin of Economics and Statistics, 52(2), 169-210. Available at: 10.1111/j.14680084.1990.mp52002003.x.

Kumar, A., Schei, T., Ahenkorah, A., Caceres Rodriguez, R., Devernay, J. M., Freitas, M., \& Liu, Z. (2011). Hydropower. IPCC special report on renewable energy sources and climate change mitigation, 437-496.

Kwiatkowski, D., Phillips, P. C. B., Schmidt, P., \& Shin, Y. (1992). Testing the null hypothesis of stationary against the alternative of a unit root. Journal of Econometrics, 54, 159-178. Available at: 10.1038/nn 1802.

Lean, H. H., \& Smyth, R. (2010). Multivariate Granger causality between electricity generation, exports, prices and GDP in Malaysia. Energy, 35(9), 3640-3648. Available at: https://doi.org/10.1016/j.energy.2010.05.008.

MacKinnon, J. G., Haug, A. A., \& Michelis, L. (1999). Numerical distribution functions of likelihood ratio tests for cointegration. Journal of Applied Econometrics, 14(5), 563-577. Available at: https://doi.org/10.1002/(sici)10991255(199909/10)14:5<563::aid-jae530>3.0.co;2-r.

Mahalik, M. K., Babu, M. S., Loganathan, N., \& Shahbaz, M. (2017). Does financial development intensify energy consumption in Saudi Arabia? Renewable and Sustainable Energy Reviews, 75, 1022-1034. Available at: https://doi.org/10.1016/j.rser.2016.11.081.

Narayan, P. (2005). The saving and investment nexus for China: Evidence from cointegration tests. Applied Economics, 37(17), 1979-1990.

Ohler, A., \& Fetters, I. (2014). The causal relationship between renewable electricity generation and GDP growth: A study of energy sources. Energy Economics, 43, 125-139. Available at: https://doi.org/10.1016/j.eneco.2014.02.009.

Omri, A., Mabrouk, N. B., \& Sassi-Tmar, A. (2015). Modeling the causal linkages between nuclear energy, renewable energy and economic growth in developed and developing countries. Renewable and Sustainable Energy Reviews, 42, 1012-1022. Available at: https://doi.org/10.1016/j.rser.2014.10.046.

Payne, J. E. (2010). Survey of the international evidence on the causal relationship between energy consumption and growth. Journal of Economic Studies, 37(1), 53-95. Available at: 10.1108/01443581011012261.

Pedroni, P. (2000). Fully modified OLS for heterogeneous cointegrated panels. Advances in Econometrics, 15, 93-130. Available at: 10.1016/S0731-9053(00)15004-2.

Pedroni, P. (2004). Panel cointegration: Asymptotic and finite sample properties of pooled time series tests with an application to the PPP hypothesis. Econometric Theory, 20(3), 597-625. Available at: 10.1017/So266466604203073.

Perron, P. (1997). Further evidence on breaking trend functions in macroeconomic variables. Journal of Econometrics, 80(2), 355385. Available at: https://doi.org/10.1016/s0304-4076(97)00049-3.

Pesaran, M. H., Shin, Y., \& Smith, R. J. (2001). Bounds testing approaches to the analysis of level relationships. Journal of Applied Econometrics, 16(3), 289-326

Phillips, P. C. B., \& Perron, P. (1988). Testing for a unit root in time series regression. Biometrica, 75(2), 335-346. 
Sadorsky, P. (2009a). Renewable energy consumption, CO2 emissions and oil prices in the G7 countries. Energy Economics, 31 (3), 456-462. Available at: 10.1016/j.eneco.2008.12.010.

Sadorsky, P. (2009b). Renewable energy consumption and income in emerging economies. Energy Policy, 37(10), $4021-4028$.

Sadorsky, P. (2010). The impact of financial development on energy consumption in emerging economies. Energy Policy, 38(5), 2528-2535. Available at: https://doi.org/10.1016/j.enpol.2009.12.048.

Shahbaz, M., Hye, Q. M. A., Tiwari, A. K., \& Leitão, N. C. (2013). Economic growth, energy consumption, financial development, international trade and $\mathrm{CO} 2$ emissions in Indonesia. Renewable and Sustainable Energy Reviews, 25, 109-121. Available at: https://doi.org/10.1016/j.rser.2013.04.009.

Solarin, S. A., \& Ozturk, I. (2015a). On the causal dynamics between hydroelectricity consumption and economic growth in Latin America countries. Renewable and Sustainable Energy Reviews, 52, 1857-1868. Available at: 10.1016/j.rser.2015.08.003.

Solarin, S. A., \& Ozturk, I. (2015b). On the causal dynamics between hydroelectricity consumption and economic growth in Latin America countries. Renewable and Sustainable Energy Reviews, 52, 1857-1868. Available at: 10.1016/j.rser.2015.08.003.

Solow, R. M. (1956). A contribution to the theory of economic growth. The Quarterly Journal of Economics, 7O(1), 65-94. Available at: $10.2307 / 1884513$.

Soytas, U., \& Sari, R. (2006). Energy consumption and income in G-7 countries. Journal of Policy Modeling, 28(7), 739-750. Available at: https://doi.org/10.1016/j.jpolmod.2006.02.003.

Stern, D. I. (2011). The role of energy in economic growth. Ecological Economics Reviews, 1219(February), 26-51. Available at: $10.1111 / \mathrm{j} .1749-6632.2010 .05921 . x$.

Tugcu, C. T., Ozturk, I., \& Aslan, A. (2012). Renewable and non-renewable energy consumption and economic growth relationship revisited: Evidence from G7 countries. Energy Economics, 34(6), 1942-1950. Available at: 10.1016/j.eneco.2012.08.021.

Warr, B. S., \& Ayres, R. U. (2010). Evidence of causality between the quantity and quality of energy consumption and economic growth. Energy, 35(4), 1688-1693. Available at: https://doi.org/10.1016/j.energy.2009.12.017.

Yah, N. F., Oumer, A. N., \& Idris, M. S. (2017). Small scale hydro-power as a source of renewable energy in Malaysia: A review. Renewable and Sustainable Energy Reviews, 72, 228-239. Available at: https://doi.org/10.1016/j.rser.2017.01.068.

Zivot, E., \& Andrews, D. W. K. (1992). Further evidence on the great crash, the oil-price shock, and the unit-root hypothesis. Journal of Business \& Economic Statistics, 10(3), 251-270. Available at: 10.1198/073500102753410372. answerable for any loss, damage or liability etc. caused in relation to/arising out of the use of the content. 